ESCRITAS Vol. 8 n. 2 (2016) ISSN 2238-7188 p. 310-329

\title{
VOZES DO CAMPESINATO FEMININO: (DES) DOBRANDO CULTURAS E MEMÓRIAS DAS LUTAS TAMBÉM PELA TERRA NO SUDESTE DO PARÁ
}

\author{
VOICES OF WOMEN'S PEASANT: (UN) FOLDING CULTURES AND \\ MEMORIES OF THE STRUGGLE FOR LAND IN SOUTHEAST OF PARÁ
}

Idelma Santiago da Silva ${ }^{1}$

Hiran de Moura Possas**

\begin{abstract}
RESUMO
O artigo pretende decantar de vozes icônicas de mulheres camponesas, do sudeste do Pará, suas experiências e agenciamentos desdobrando culturas parciais do campesinato. Tratam-se de mulheres, pela voz, trazendo à tona memórias da luta pela terra de um lugar de poder ainda desigual, mas não mais inexistente no interior das versões hegemonizadas pelos homens. São narrativas que apresentam diferenças, por isso alargam o campo da resistência camponesa na produção de sentidos as suas lutas. Encontramos mulheres, em corpo-voz, numa perspectiva relacional (a sua condição de classe e de gênero), intersticial (desdobrando a cultura e a memória camponesa no sudeste do Pará), como também em tons agonísticos (agenciando um campo de luta no limiar da inexistência/existência).
\end{abstract}

PALAVRAS-CHAVE: Mulheres Camponesas, memórias, oralidade, luta pela terra.

\begin{abstract}
The article intends to elutriate iconic voices of rural women, their experiences and agency unfolding partial culture of the peasantry in southeastern Pará. The voice of these women brought out the memories of the struggle for land in the southeast of Pará, where there were still unequal distribution of power, but not non-existent into the hegemonic versions made by men. Its narratives show the different, and so widening the field of peasant resistance in the production of meaning to their struggles. We find women, body-voice in a relational perspective (your class and gender condition), interstitial (unfolding culture and peasant

\footnotetext{
${ }^{1}$ Doutora em História pela Universidade Federal de Goiás. Professora Adjunta da Universidade Federal do Sul e Sudeste do Pará, lotada no Instituto de Ciências Humanas, Faculdade de Educação do Campo e no Programa de Pós-Graduação em Dinâmicas Territoriais e Sociedade na Amazônia. Coordena o Grupo de Pesquisa Culturas, Identidades e Dinâmicas Sociais na Amazônia Oriental brasileira, cadastrado no CNPq e autenticado pela UNIFESSPA.idelma@unifesspa.edu.br.

** Doutor em Comunicação e Semiótica pela Pontifícia Universidade Católica de São Paulo. Professor da Universidade Federal do Sul e Sudeste do Pará - Faculdade de Educação do Campo. Integrante do Grupo de Pesquisa - CNPq: Comunicação e Cultura: Barroco e Mestiçagem/PUC-SP e líder do Grupo de Estudos Interculturais das Amazônias/UNIFESSPA-CNPq. hiranpossas@unifesspa.edu.br.
} 
memory in southeast of Pará), as well as agonistic (touting a fighting field on the threshold of absence / existence).

KEYWORDS: Rural Women, memoirs, orality, struggle for land.

Eu não posso me dar ao luxo de lutar por uma forma de opressão apenas...

Audre Lorde

\section{MULHERES, AGENCIAMENTOS, DISCURSOS E MEMÓRIAS}

Esse exercício, desejando ser um palimpsesto com vozes autorais, epistêmicas e de mundos - uma proposta de simbiose com as malhas discursivas-memoriais de duas mulheres camponesas do sudeste do Pará, Amazônia Oriental brasileira - decanta, das experiências de seus corpos vibráteis ${ }^{2}$, seus agenciamentos desdobrando as culturas parciais do campesinato em regimes de acoplagens no fora do dentro e a parte no todo (BHABHA, 2011). Trata-se, até certo ponto, de um agenciamento maquínico - "ele não é produzido por, mas por natureza é para uma coletividade" (ZOURABICHVILI, 2004, p.10)- não reduzido a um simples dado auto-evidente, mas de um pronunciamento dos mundos que, simultaneamente, as criou e que elas recriam. São discursos femininos inscrevendo, sem a pretensão aqui de se extrair significações precisas, nas experiências e nas memórias da luta pela terra na região.

Mesmo com o intento hercúleo em dar vasão a algumas das malhas discursivas dessas mulheres camponesas e o reconhecimento de alguns de seus labores agenciais, não há, aqui, pretensão de se falar por um outro, principalmente levando-se em consideração o fato desse outro tratar-se de mulheres subalternas:

\footnotetext{
uma posição ainda mais periférica pelos problemas subjacentes às questões de gênero [...] se no contexto da produção colonial, o sujeito subalterno não tem história e não pode falar, o sujeito subalterno feminino ainda está mais ainda na obscuridade (SPIVAK, 2010, p. 17).
}

Dadas as circunstâncias, transitamos, nesse exercício epistêmico, também por essa ‘impossibilidade', mas desejando urdir, por meio de uma rede mais dialógica, espaços nos quais "o subalterno possa se articular e como consequência, possa ser ouvido" (SPIVAK, 2010, p. 17). Subalternidade, nesse contexto, revestida por várias 'camadas': mulheres negras, camponesas, sem terra, e, em muitas situações, experienciando, em significativa medida, silenciamentos nos espaços decisórios dos movimentos sociais.

\footnotetext{
${ }^{2}$ Para Suely Rolnik (2014), seriam paisagens psicossociais sensíveis aos efeitos dos encontros e suas reações, como atrações, repulsas, afetos e território de inteligibilidades e de intensidades.
} 
Do espaço desse artigo emerge parte de um mundo-amazônico-oriental, não tão diverso das regiões planetárias testemunhando a 'dança', em suas múltiplas versões, do grande capital ao orquestrar espetáculos, milagres e catástrofes, "ciclos viciosos da interminável reprodução expansiva do ganhar dinheiro a fim de ganhar dinheiro" (ZIZEK, 2014, p. 32). 'Todos' tentados a se converterem a simples e cinicamente `a força de trabalho ou remessas de mercadorias, um modo comum de condução, reprodução e controle de subjetividades 'fadadas' aos agenciamentos facistóides ditados para as formas de expressão e de rememoração. Seria como se algo, em nossos corpos vibráteis, estivesse "com direitos ainda cassados ou ameaçados de sê-lo a qualquer momento" ( ROLNIK, 2014, p. 169).

A tradução - uma tentativa de comunicação entre culturas - desvela memórias femininas, fenômenos materiais, corpóreos, psíquicos e ainda fenômenos de culturas, e será, por cá, um modo especial de presentificar a vida em muitos atos e formas específicas do lembrar, que pode vir do re-cordar ao re-lembrar; lembrar esquecendo ou simplesmente esquecer. Então tudo ${ }^{3}$ será memória e seu par complementar: o esquecimento. Há ainda a comentar a força de toda uma memória subterrânea camponesa, daquela que se desenrola como algum tipo de resistência ao que foi recalcado e perseguido e que recrudesce com uma vitalidade ímpar. Memória com essas mulheres é mais do que um apoio, é matéria prima; é lugar; eclosão de experiências; ponto de partida ou intercessão do passado ou mesmo do futuro. Esses lembrares arregimentam falas e gestos, corpo e mente, o legado dos mortos e a presença dos vivos nos conflitos pela luta da terra. Memórias sempre, em transmissão, como ato seletivo, informacional e comunicacional (PIRES FERREIRA, 2004).

As rememorações, às vezes erráticas e opacas, tornam-se um solo fértil para a análise de conflitos éticos, políticos e de um palco de batalhas ininterruptas pela hegemonia dessas reminiscências. Mesmo contemporâneas de uma região do planeta na qual as 'queimas de arquivo' são constantes, suas vozes reconstroem pelo dúctil e complexo mecanismo da consciência. A negociação com o passado nem sempre é uma ação bem sucedida ou prazerosa, pois questões mal resolvidas podem se tornar verdadeiros obstáculos, para a construção de uma representação cultural, assim como histórias confortavelmente repetidas, não parecem ser as fontes mais adequadas para a composição de uma memória alternativa. Assim, as lembranças não são representações exatas do passado, mas trazem aspectos desse passado, para que se ajustem às nossas aspirações atuais (THOMSON, 1997).

\footnotetext{
${ }^{3}$ As ideias de Marcel Proust, especialmente as dedicadas à memória em seus sete tomos, permeiam estudos de diferentes pesquisadores, dentre os quais, destacamos as pesquisas de Jerusa Pires Ferreira e Walter Benjamin. Nelas as categorias memória voluntária e involuntária dão melhor aparência ao que chamamos simploriamente de lembrança e de esquecimento.
} 
Provocadas pelo oral, essas 'recordações' ditadas por certas doses de 'esquecimentos', são instrumentos de certa instabilidade e maleabilidade, mas restituem aos discursos mais abafados a recriação de um passado que é permissível conviver, forma pela qual, nas 'mesas de negociação', esse construto representativo se impõe aos olhares prontos e acabados daqueles que insistem em obrigar a humanidade a confessar raças, ideologias e religiões - se não em tribunais, ao menos em formulários oficiais (THOMSON, 1997).

\section{ZEFA E DAGMAR: INTENSIDADES SEM-TERRA}

Tramada a teia temática, a voz é de Josefa Sousa e Silva Albuquerque (Zefa), casada, 48 anos, negra, residente no Projeto de Assentamento (PA) Grande Vitória ${ }^{4}$, município de Marabá ${ }^{5}$. Foi constituída liderança camponesa do Movimento Sindical dos Trabalhadores e Trabalhadoras Rurais (MTTR), a partir de sua decisão de participar de um acampamento em 1996. Esse é um momento de transição nas estratégias e representações dos coletivos de luta pela terra na região. O intercâmbio entre o movimento sindical, historicamente identificado pela 'luta posseira', e o Movimento dos Sem Terra (MST) concorre para transformações (auto-alter) identitárias, passando a predominar a nomeação 'sem-terra' e o uso da estratégia do acampamento (PEREIRA, 2013).

Nesse período, a prioridade da luta se voltava, segundo sua memória voluntária ${ }^{6}$, para o enfrentamento e negociações com as políticas de reforma agrária do Estado brasileiro e não mais ou somente o enfrentamento direto com os grandes proprietários rurais. Daí que Maria Dagmar Ferreira de Sousa, outra entrevistada ${ }^{7}$, resida atualmente em um acampamento. Essa categoria foi ampliada, na contingência da luta pela terra, incorporando desde a estratégia de 'ocupação' da terra à condição jurídico-formal de como permanecem nela (em espaços coletivos ou nos lotes familiares) antes da criação do assentamento de reforma agrária. Assim, o acampamento traduz-se como estratégia de 'ocupação' e resistência na terra, incluindo, por exemplo, o desenvolvimento de práticas produtivas. Por isso, ele é também o resultado de um agenciamento frente a política de reforma agrária do governo brasileiro, cujas

\footnotetext{
${ }^{4} \mathrm{O}$ PA Grande Vitória até recentemente pertencia a outro município, Itupiranga.

${ }^{5}$ É um município brasileiro situado no estado do Pará. Pertencente à mesorregião do Sudeste Paraense, Marabá está a sul da capital do estado distando desta, cerca de 500 quilômetros. Sua localização tem por referência, o ponto de encontro entre dois grandes rios, Tocantins e Itacaiúnas, formando uma espécie de "y" no seio da cidade, vista de cima. É formada basicamente por seis distritos urbanos interligados por rodovias.

${ }^{6}$ A memória na qual o personagem-narrador consegue invocar, tendo a consciência disso, para Proust (1981) é a lembrança flamejante da consciência.

${ }^{7}$ As entrevistas foram gravadas e transcritas, e caracterizam-se como de tipo híbridas, isto é, misto de entrevista de história de vida e temática. Neste trabalho, participaram duas bolsistas de Iniciação Científica (PIBIC), Kézia Vieira de Souza e Maria Marlete Ferreira Gomes. Esta pesquisa foi apoiada pelo CNPq - Ciências Humanas e Sociais.
} 
medidas (parciais) somente ocorrem sob pressão social, além de, simultaneamente, criminalizar os sujeitos coletivos da luta pela terra.

Dagmar se diz natural de Martins Olímpio-PI, casada, 52 anos, atualmente acampada no Tibiriça ${ }^{8}$. Mãe de quatro filhos (duas mulheres e dois homens), agricultora familiar que vivenciou, desde a infância, o processo de migração por vários estados brasileiros, em busca de terra: Piauí - Maranhão - Tocantins - Pará. Essa é uma recorrência na história do campesinato no sudeste paraense, a migração intergeracional em busca de terra e trabalho em direção a Amazônia Oriental brasileira. Outra recorrência, nessa trajetória, é o trabalho subordinado ao dono da terra e pela expropriação de parcela da produção agrícola. Somente no Pará, Dagmar realizou o projeto de trabalhar em terra própria. O 'sentido da roça' tece sua narrativa de história de vida pela articulação das categorias família-trabalho-terra-luta e por expressar 'uma maneira de viver e de ser', certo ethos do trabalho integrando os processos de socialização que "sedimenta as relações intrafamiliares e entre unidades familiares, além de assegurar laços de reciprocidade necessários para a reivindicação e defesa do território" (ALMEIDA, 2008, p. 39-40).

Josefa Sousa e Silva e Maria Dagmar Ferreira de Sousa elegem como lócus para suas enunciações ${ }^{9}$ as reminiscências da luta pela terra. A primeira elege a luta sociopolítica no movimento sindical dos trabalhadores e trabalhadoras rurais como cenário social para o uso da palavra e como prática fundamental das relações de poder e de gênero. A segunda ressalta o trabalho na terra, como cena sociocultural acionando seu verbo memorial. Desse lugar, anuncia-se como protagonista de um cotidiano da luta camponesa.

As vozes dessas mulheres ressoam e participam, dupla e ambivalentemente, da construção de quadros da memória social camponesa sobre os processos de ocupação da região sudeste do Pará. Neste aspecto, ressalta-se que a ocupação da Amazônia tem sido parte de um processo que rasura as fronteiras entre a 'esfera pública' e a 'ação privada'. De um lado, porque o Estado e o Capital compartilham de um projeto civilizador para a Amazônia no qual a gestão da 'colonização' visa o ordenamento territorial em favor do segundo, ao explorar e expropriar o trabalho, as riquezas, os valores e os saberes (CASTRO, 2010). De

\footnotetext{
${ }^{8} \mathrm{O}$ Acampamento Tibiriçá, localizado a $17 \mathrm{~km}$ da cidade de Marabá, é resultado de uma ocupação realizada no ano de 2003, por trabalhadores rurais ligados ao STTR de Marabá. Desde então, foram despejados da área por duas vezes e retornaram. As famílias permanecem cada uma em seu lote demarcado pelos próprios acampados em casas de "pau a pique", produzindo culturas anuais e criando pequenos animais.

${ }^{9}$ Associado ao conceito sócio-histórico do signo de Bakhtin concebe-se os praticantes da linguagem "sempre situados socialmente em determinados contextos ideológicos, históricos e sociais, marcados por todas as variáveis existentes nesses contextos (classe social, sexo, faixa etária, origem geográfica etc.). [...] Tal conceito de contexto e de condições sócio-históricas de produção e de interpretação é chamado por Bhabha de lócus de enunciação". (SOUZA, Lynn, 2004, p.119)
} 
outro, porque agentes sociais subalternizados têm se constituído em 'unidades de mobilização' assumindo "sob condições de existência coletiva uma posição de sujeitos sociais" (ALMEIDA, 2008, p. 38.) e, desde essa diversidade social, agenciam para obtenção de ganhos políticos frente ao Estado.

Elas se reconhecem participantes de uma comunidade de sentidos (projetoidentidade-memória), valendo-se de um repertório memorial socialmente relevante ( VELHO, 1994), desenhado por vínculos sociais e campos de pertencimento e antagonismo comuns: a experiência de classe. O campesinato no sudeste do Pará é marcado por processos sucessivos e intergeracionais de expropriação da terra e migrações em direção à Amazônia buscando sua reprodução sociocultural.

As diegeses dessas mulheres evidenciam a indeterminação e a liminaridade do discurso da comunidade (de classe), porque elas se (in)surgem como sujeitos da enunciação, reivindicando o direito de significar suas experiências e de polemizar com a memória hegemonizada pela ação e a palavra dos homens. Introduz uma diferença que diz respeito não somente ao conteúdo de seu enunciado, mas ao posicionamento inscrito no discurso, implicado, dentre outras, pelas relações e posições de gênero. Esses agenciamentos “desdobram a cultura parcial da qual emergem para construir visões de comunidade e versões de memórias históricas, que dão forma narrativa às posições minoritárias que ocupam" ( BHABHA, 2011, p. 91), uma possiblidade de leitura para os desdobramentos na cultura parcial do campesinato, alargando o campo da resistência camponesa na produção de sentidos para suas intermináveis lutas.

\section{VOZES DO CAMPESINATO FEMININO: OBJETOS-SUJEITOS}

A experiência da luta constitui as mulheres-narradoras, simultaneamente, em 'objetos' históricos de uma pedagogia sexista, e 'sujeitos' de um processo de significação (BHABHA, 2003). Isso implica que suas enunciações são produzidas de um lugar desigual da 'autoridade' cultural e do protagonismo político no interior da própria cultura parcial do campesinato. Evidência de como as culturas não se bastam em si mesmas, pois há relações e negociações no interior da nação (e suas pedagogias) não reduzidas a um dado a priori ou homogêneo, mas sim num discurso fronteiriço "ao mesmo tempo desconcertantemente semelhante e diverso" (BHABHA, 2011, p. 82). 
Esse é um horizonte de interpretação possível e coloca a questão de como os problemas se impõem para a investigação ou dela são decorrentes. Não se trata de procedimento sempre consciente e metodicamente controlado ou mesmo eticamente orientado. Assim, escolheu-se alguns encaminhamentos teórico-metodológicos.

Primeiro, reconhece-se que a intersubjetividade é transversal a todo processo da pesquisa e da escrita. A interpretação é relacional e modifica o objeto apreciado, porque movimenta e amalgama um duplo processo compreensivo: aquele realizado pelo narrador e aquele realizado pelo investigador.

Segundo, que o trabalho com história oral é constitutivo de práticas de saber que se realizam pelo reconhecimento mútuo, enquanto sujeitos que colaboram em práticas de conhecimento e de intervenção na realidade. Portanto, assume-se sua lida com processos de afirmação e reconstrução de subjetividades (individuais e coletivas).

Terceiro, que a narração se constitui - ela mesma - num ato que tem efeitos, especialmente na produção de diferenciação e na mobilização da memória mediante propósitos de intervenção social (CERTEAU, 1994). Ainda que a memória e a narrativa se insiram numa linguagem e numa narração prévia (FROTSCHER, 2012), por exemplo, de compartilhamento de repertórios da memória social do campesinato, elas são dinâmicas e engendram repertórios discursivos e de sentido no próprio acontecimento da entrevista ${ }^{10}$.

Quarto, quanto a narrativa oral podendo configurar-se numa estratégia de comunicação de experiência, crítica social, busca de reconhecimento e mobilização dos entrevistados na interpretação sobre suas histórias e modos de compreender o mundo (LIMA, 2003). Desta maneira, abre-se a possibilidade de composição de repertórios acerca dos pontos de vista e dos saberes das mulheres, sendo elas suas próprias testemunhas, permitindo uma aproximação da agência feminina e de especificidades de sua condição de mulheres camponesas (situações e posições que lhes são conferidas nas redes das quais fazem parte e nas quais atuam).

Mediante esses pressupostos, reconhece-se, no encontro da pesquisa, um encontro humano (antropológico) e que requer a adoção de uma perspectiva de interpretação que extrapola o espaço prescritivo da ciência rumo à possibilidade de compreensão pelo envolvimento, de reconhecimento que "há um engajamento em todo ato de compreensão" (GONSALVES, 2006, p. 253). Trata-se de reconhecer a dimensão política do conhecimento e sua participação em projetos sociais amplos ou empreendimentos teórico-práticos que visam

\footnotetext{
${ }^{10}$ Com Alessandro Portelli (1997), tencionamos e problematizamos a entrevista. Ela dificilmente pode criar uma situação de igualdade, mas ela - a entrevista - pode pedir por isto.
} 
ou não questionar o 'pensamento abissal' que, dentre outros efeitos, reduz o 'outro' ao lugar da ausência, da inexistência (SANTOS, 2010).

Por isso, a discussão realizada por Scott (SCOTT, 1992, 1995, 1999) torna-se relevante, por um lado, por evidenciar que a história das mulheres configura um campo inevitavelmente político (por tratar as relações de poder, os sistemas de convicção e prática do conhecimento e dos processos que o produzem), e, por outro lado, por problematizar a autoridade da experiência como uma noção referencial e auto evidente, ressaltando a natureza construída da experiência.

Isso exige um enfoque nos processos de produção de identidade, uma insistência na natureza discursiva da 'experiência' e na política de sua construção. Experiência é, ao mesmo tempo, já uma interpretação e algo que precisa de interpretação. $\mathrm{O}$ que conta como experiência não é nem auto-evidente, nem definido; é sempre contestável, portanto, sempre político [...] Experiência é, nessa abordagem, não a origem de nossa explicação, mas aquilo que queremos explicar. Esse tipo de abordagem não desvaloriza a política ao negar a existência de sujeitos; ao invés, interroga os processos pelos quais sujeitos são criados, e, ao fazê-lo, reconfigura a história e o papel do/a historiador/a, e abre novos caminhos para se pensar a mudança (SCOTT, 1999, p. 48).

Desse modo, interrogar os processos pelos quais emergem as mulheres na luta pela/na terra é propor ir além do projeto de torná-las visíveis como evidência incontestável, mas considerá-las na historicidade de suas experiências e das relações em que estiveram e estão inseridas, bem como considerá-las corpos enunciativos que recriam suas experiências, identificações e diferenças. A história das mulheres do campo, numa perspectiva relacional contribui, com outras posições de sujeito, para compreender e ampliar as perspectivas sobre as histórias da família, da luta pela terra, do trabalho, da organicidade dos sujeitos coletivos, das comunidades rurais, dentre outros aspectos da produção da existência dos/as camponeses/as e da história do tempo presente na Amazônia Oriental brasileira.

Reconhecer a dimensão de produção discursiva dessas experiências significa recusar a separação entre 'experiência' e linguagem, especialmente quando se propõe trabalhar com história oral, considerando que todas as categorias são contextuais, contestáveis e contingentes e que precisam ser historicizadas (SCOTT, 1999). Abordar a experiência é considerar que os sujeitos são constituídos através dela e pensá-la é historicizá-la, incluindo as representações que ela produz.

Além disso, o trabalho com as histórias das mulheres do campo no sudeste do Pará deverá colocar em questão o tema da gestão da memória coletiva, incluindo o debate sobre memórias públicas e processos de democratização da memória. A "história oral de mulheres não apenas traz de volta à superfície parcelas da experiência feminina, mas também contribui para enfocar os mecanismos de inclusão e exclusão que regem memórias públicas”, 
visando pensá-la como direito de cidadania, isto é, a "necessidade de um arcabouço público no qual as memórias de todos possam ser reconhecidas e, ao mesmo tempo, elas próprias possam se reconhecer" (SALVATICI, 2005, p. 36).

De tal modo, é possível que seu desenvolvimento constitua em mais uma experiência social na dinâmica de representações das mulheres do campo, vindo a produzir novos significados e posicionamentos. A investigação poderá incidir na instituição de um 'objeto' interveniente no processo discursivo da memória coletiva da luta pela/na terra no sudeste do Pará, ou seja, constituir o discurso como espaço de resistência por produzir o objetivo do desejo político ${ }^{11}$.

\title{
A EXPERIÊNCIA DA LUTA PELA TERRA: DOS SENTIDOS DA ROÇA E DA PALAVRA VERSUS A PRODUÇÃO CULTURAL DE INEXISTÊNCIA PRODUTIVA E POLÍTICA
}

As mulheres, no processo da luta pela terra, têm assumido papel fundamental, caracterizado pela polivalência de atividades e tarefas, inclusive no período da luta posseira.

\begin{abstract}
Embora muitos grupos de posseiros tenham sido formados, no primeiro momento das ocupações, só por homens, muitas mulheres estavam lá fazendo parte do confronto armado. Elas não só ajudavam os homens nos serviços das roças, nas construções de casas e nas reuniões, mas foram também vítimas da violência não só porque viram os seus esposos, filhos, pais e amigos sendo torturados e assassinados, mas porque foram estupradas, espancadas e também assassinadas. Em diversos momentos, recaíram sobre elas a responsabilidade de proteger os seus maridos, filhos e amigos, escondendo-os dentro ou no quintal da casa, enfrentando, às vezes, fisicamente, os pistoleiros pedindo, sob lágrimas, que não os assassinassem ou mesmo fugindo para direções opostas onde estavam os homens escondidos para despistar os criminosos. Há casos em que elas se colocaram em fuga levando crianças e alguns utensílios domésticos, no meio da noite, à procura de um lugar seguro. Em outros momentos, estando na cidade, enviavam recados para os grupos de posseiros avisando-os sobre alguma diligência da polícia ou de um suposto ataque de pistoleiros. Em certas situações, eram elas que levavam munições para os homens entrincheirados, passando por barreiras policiais ou mesmo fazendo chegar ao STR, ao bispo, ao padre e à CPT as informações ou denúncias da violência contra comunidades de posseiros ( PEREIRA, 2013, p. 137-138).
\end{abstract}

\footnotetext{
${ }^{11} \mathrm{O}$ presente enunciativo como lócus da agência histórica e social do sujeito coloca em pauta a relação entre identidade, posição de sujeito e mudança social, pois o "fechamento arbitrário" do signo, isto é, sua natureza contingente é "também o espaço cultural para a abertura de novas formas de identificação que podem confundir a continuidade das temporalidades históricas, perturbar a ordem dos símbolos culturais, traumatizar a tradição". (BHABHA, 2003, p. 250)
} 
No período recente, da luta 'sem terra', tanto no âmbito do MST (Movimento dos $\begin{array}{llllll}\text { Trabalhadores } & \text { Rurais } & \text { Sem } & \text { Terra) } & \text { como } & \text { MTTR }\end{array}$ (Movimento Sindical dos Trabalhadores e Trabalhadoras Rurais), os acampamentos são realizações coletivas de homens, mulheres, jovens e crianças. Esse espaço de vivência propicia trocas de experiências, distribuição e atribuição de tarefas, solidariedade e formação contribuindo, para a ressignificação dos papéis de gênero e geração, dentre outros.

As duas mulheres entrevistadas para este trabalho - Dagmar e Zefa - revelam trajetórias de vida com singularidades, porém, elas se cruzam na experiência social formadora da luta pela terra. O acampamento é uma experiência comum. Para Zefa, o acampamento próximo à terra reivindicada, às margens de uma rodovia, marcou um momento de ruptura na sua trajetória de vida pela sua inserção num espaço sociopolítico. Já Dagmar, vivenciou o acampamento na sua fase de resistência na terra e ele é pronunciado como um prolongamento e desdobramento da luta pela reprodução sociocultural da família camponesa, ressaltando o trabalho na terra como lócus de narrativa e genealogia.

Para Dagmar, "os momentos importantes de sua vida aparecem para reforçar a sua trajetória direcionada à "luta pela terra" (GUIMARÃES, 2010, p.70). Da infância ao casamento, o trabalho agrícola em 'terras alheias'.

\footnotetext{
Aí continuei trabalhando nas roças com meu pai, ele fazia aquelas roças distantes, nós levantava cedinho da manhã e peitava no mundo. Lá, se era tempo da queimada daquela roça, nós ia ajuntar garrancho igual tá ali, tudo limpim. Quando terminava meu pai ia plantar e nós ia limpar o chão arrancando o mato. Aí, certo que nessa rotina, eu fiquei trabalhando com meu pai. Meu pai perguntava: minha filha, você gosta de trabalhar? -Papai, eu gosto, eu tô achando muito bom, porque aqui eu me dedico direitinho, eu sei o que eu tô fazendo no meu serviço. Então continuei trabalhando mais meu pai.

[Depois do casamento] Aí quando nós chegou, começou a mesma rotina, trabalhando na roça porque ele [o marido] era pobrezinho também, igual eu. Aí, fazia aqueles pedacinhos de roça, mas nas terras alheias porque nós não tinha, e nem ele. Nas terras alheias, aquilo... Ele fazia aquela rocinha, nós só tinha direito de plantar arroz, milho, outra coisa não tinha como plantar, porque o dono não deixava nós plantar outro tipo de coisa... Aí nós colhia (SOUSA, 2013).
}

A mudança com o marido para o Pará foi motivada pelo projeto de conquistar uma terra para trabalhar: "como nós tem o sonho de encontrar um lugar pra nós trabalhar sendo nosso, nós vamos procurar" (SOUSA, 2013). A migração, ocorrida em 1984, para a comunidade do Tracuá (distante $218 \mathrm{~km}$ da cidade de Marabá) foi possível devido à rede de parentesco que já se encontrava na região. 
Aí chegou um parente dele, um tio dele lá na nossa casa. Esse tio dele era daqui do Pará então ele chegou -meus filhos, vocês trabalhando aqui tal... -é que não tem outra opção, nós não tem como possuir uma terra, nós tamos trabalhando nas terras alheia, - meu fie, se você quiser me acompanhar trabalhar e arrumar um pedaço de terra pra vocês trabalharem, vocês vão pra onde eu tô. Só que eu vou dizer, é dificultoso, mas lá vocês consegue, que hoje ainda tem como conseguir. Eu fiquei muito alegue. - nós vai? Ele disse: - não, é o seguinte: eu vou fazer assim. Aí o tio dele contou tudo direitinho pra ele, distância, a dificuldade, tudo. Tá bom. Aí ele falou: - pois é eu vou olhar lá e você fica. Eu já queria ir. Ele disse: - não! você fica eu vou olhar eu vou ver como é a distância e ver lá todinho se lá ser bom, se ser como meu tio tá dizendo, aí quando eu chegar vou trazer todas as informações. -Tá bom. Então, assim ele fez ( SOUSA, 2013).

\title{
Apesar das dificuldades anunciadas para o deslocamento e estabelecimento na
}

terra, Dagmar ressalta sua participação ativa na decisão de migrar.

\begin{abstract}
Aí ele foi contar a historinha: -você não vai aguentá a distância, olha é vinte cinco dias de a pés. Que só tinha carro lá da onde nós morava, do Tocantins até aqui em Marabá e até uma senhora de Três Poderes aonde o carro ia. Aonde o carro ficava era vinte e cinco dias de viagem pra chegar no destino. Eu digo: - mas eu aguento, mas vamos lá! Tu agradô? Dá de nós conseguir um pedaço de terra? -Dá, dá... -Nós vai? Não temos nada aqui mesmo! Só tem casinha de palha. [...] Até onde foi carro muito bem, aí ele disse - agora daqui pra frente é no pé. -Umbora ver o que vai dar. Aí não tinha estrada, era uma varedinha assim, só via o ritmo, só aquela batida. [...] Aí ele me perguntava: -Tá cansada? -Tô não. -Pois é, já merendemo vamos embora. Peitemo caminhando, caminhando, caminhando, quando dava seis horas da tarde, a gente achava um morador. De seis a seis [horas] nós topava a casa de um morador. Aí chegava lá, nós pedia hospedagem as pessoas davam, aí nós dormia, quando dava seis hora da manhã de novo essa rotina. Foi vinte e cinco dias, [...] eu já ia com as minhas pernas estava dessa grossura de inchada todas duas, a palma do meu pé ia assim, parece que tinha espim, que eu ia patiando. Eu disse: - Toim, tô pra não agüentá mais, olha ai como tá minha situação. -É, mas já tá perto. [...] Nós sofreu muito pra chegar até lá. Eu falo pra meus filhos: - Meus filhos, acho que ainda hoje, eu sinto meus pés doído do que eu sofri pra ganhar aquela terra, mas lutei e ganhei e tô satisfeita (SOUSA, 2013).
\end{abstract}

A família de Dagmar permaneceu nesta terra (localidade) por 16 anos, mantendo as atividades produtivas no lote. Com os filhos precisando de escola, ela foi com eles para a cidade de Marabá, não permanecendo por muito tempo, pois sentia-se deslocada sem a possibilidade da relação com o trabalho na terra.

Aí eu digo, agora chegou a época deu tá junto como meus filhos, vou deixar a rocinha, porque eu tenho que estar junto com meus filhos, que ainda era criança [...]. Então agora chegou a hora deu tá com eles. Aí fiquei por lá mais eles, mas eu me sentia assim, com vontade de trabalhar, eu dizia - meus fie, aqui acho tão pequeno pra mim tá andando, as vezes eu não achava nada pra fazer, eu varia meu terreiro duas vezes, eu fico assim tem hora que dá um calor de febre porque não tô me movimentando. Aí as meninas: -mãe, quieta. Eu digo: -minha fia eu tô sentindo saudade da minha roça. Ela disse -não mãe, com o tempo a senhora vai acostumar. Pode ser que eu acostume, mas fica um pouco difícil, mas a gente não esquece do serviço da roça (SOUSA, 2013). 
Em 2006, a família de Dagmar ${ }^{12}$ entrou para o Acampamento Tibiriçá, próximo à cidade de Marabá. Desde então, ela é acampada assumindo novamente um papel fundamental na conquista da terra, uma vez que ela permanece cotidianamente no lote, a maior parte do tempo sozinha, realizando várias atividades domésticas e agrícolas. Ela ressalta a gestão familiar do trabalho na terra como um dos saberes das culturas camponesas.

\begin{abstract}
Meus filhos sabem fazer de tudo. Eles estudam, tem deles formado, mas eles sabem trabalhar o serviço da cultura familiar. Eles sabem tudo [...], -meu fie vai fazer aquilo ali, vai roçá aquele pé de mato ali, ele roça, ele capina, ele sabe colher. Meu fie vai arrancar uma macaxeira, vão plantar um pé de mandioca, aquela terra tá limpa vamos plantar. -Vamos. Aí junta eu, meus filhos, mulher e homem, marido um vai cavando outros vai plantando e outros vão fazendo o almoço e assim nós trabalha, nós trabalha tudo combinado, tudo juntinho, e tudo que um vai fazer nós combina com os outros. -Pode fazer? Será que vai dá certo? Aí nós vamos, continuando trabalhar. É isso nosso tipo de trabalho na roça, assim nós combina com os outros. -Vamos fazer isso... Será que vai dá certo? Umborá trabalhar. Então é o caso deu tô aqui dentro lutando e eles também [...], e quando eles têm tempo eles vêm trabalhar mais eu (SOUSA, 2013).
\end{abstract}

Scott (1999), a partir dessa trajetória vocalizada por Dagmar, poderia dialogar com a questão. Não seriam os indivíduos donos de experiências, mas sim reconstruídos por ela. Thompson (1981), sobre a mesma questão, percebe que as experiências humanas não são apenas pensadas, mas também sentidas: "Eu trabalho eu fico assim na roça, é porque eu me sinto tão bem, mas tão bem, eu me sinto... Dentro da roça eu gosto" (SOUSA, 2013).

A narrativa de Dagmar não tem o sentido do apego a uma tradição que não pode ser quebrada. Pelo contrário, evidencia um enunciado carregado de resistência: da mulher como agente produtiva na agricultura camponesa.

[...] porque eu gosto muito de tá mesmo é dentro da terra. Eu gosto de tá é ali mesmo, mim movimentando, plantando, capinando, fazendo uma coisa. Quando eu não acho outro tipo de serviço assim pra mim fazer, eu vou ali no cocauzinho que têm, ajunto coco.[...], mas eu não paro de trabalhar, mas eu gosto de fazer tudo isso, porque me sinto bem. [...], mas foi minha luta, eu lutei muito, hoje eu vivo cansada já um pouco, por causo da idade que eu tenho. É, eu comecei trabalhar muito nova, eu tinha 12 anos de idade quando eu peguei a luta do trabalho assim, mas eu me sinto bem, ainda hoje eu faço meus serviços (SOUSA, 2013).

A luta é uma categoria recorrente na voz de Dagmar. Sua leitura, quando a usa, refere-se ao fato de que sua história: nunca esteve pronta, sempre foi uma conquista que dependeu de sua ação e da interação com os outros (família, acampados, etc.). "Ter uma terra

12 O marido de dona Dagmar é sindicalista. Foi presidente do STTR de Marabá e, atualmente, é um dos dirigentes da FETAGRI/ Sudeste do Pará. 
pra mim ficar, dizendo esse aqui é meu, eu lutei tanto tempo pra mim hoje ser dona dela. Não é nem pelo trabalho, foi pela luta pra mim ganhar ela" (SOUSA, 2013).

Entrelaçadas à luta, terra e trabalho são categorias integradoras do discurso e dos espaços de vida e de pertencimento dessa mulher - Dagmar - uma vez que, “[...], é tão tal que eu gosto da roça, vou the explicar bem direitim, eu gosto muito do sentido da roça, além de eu já ser acostumada na luta da roça assim". Seu corpo ${ }^{13}$, ou melhor, as marcas do seu corpo, são esculpidas pelo trabalho 'pesado': "uma mulher toda encarcada assim, encarcada como carne de homem [...], minha carne é partida que nem de homem. Eu acho que é por isso que tem muita resistência" ( SOUSA, 2013).

A narrativa de Dagmar reforça sua identificação com o espaço físico-social e o trabalho desenvolvido, enquanto produção de si como ser humano e como produção cultural mais ampla - o 'sentido da roça' - constituição de um (des)dobramento da cultura camponesa, acrescentando-lhes novos sentidos, pois ressalta o trabalho como produção cultural, seja ele nas dimensões - material e imaterial ou de um no outro - do cotidiano da resistência, contribuindo para a constituição de uma comunidade afetiva.

Josefa Sousa Silva Albuquerque, a Zefa, não viveu a experiência da migração nem o trabalho na terra antes de se tornar assentada. Ela vivia na cidade de Marabá e trabalhava numa serraria quando decidiu ir para o Acampamento Santa Maria, às margens da rodovia Transamazônica, em 1996. Seu lócus de enunciação é o da mulher que se constituiu liderança do MTTR de Itupiranga e da Associação dos Assentados do PA Grande Vitória, assim como assumiu a Secretaria de Gênero da FETAGRI (Federação dos Trabalhadores da Agricultura do Estado do Pará - Regional Sudeste). Hoje, aos 48 anos de idade, por motivo de saúde e para cuidar do 'seu' lote, se afastou da militância.

A decisão de ir para o Acampamento foi de Zefa. O marido foi convencido depois, inclusive pelo fato de somente eram incluídos na lista dos acampados os homens.

\footnotetext{
Quando eu fui no acampamento pra colocar meu nome eu fui junto com esse vizim lá que eu tinha falado. Meu marido pro serviço. Aí quando nós chegou lá ele [vizinho] me apresentou, na mesma hora veio um líder que era um senhor de Joao Piauí, aí disse: -olha, mas a senhora não pode botar seu nome não, a senhora não pode botar seu nome tem que botar o nome do seu esposo (ALBUQUERQUE, 2013)
}

\footnotetext{
${ }^{13}$ Para o pesquisador Paul Zumthor (2000), a oralidade não pode ser dissociada do corpo e de todos os seus desdobramentos: marcas, suores e gestos. Corpo seria a voz em presença.
} 
Esse dado tem duas genealogias: o gênero operando como uma "forma primária de dar significados às relações de poder" e o gênero como "constitutivo de relações sociais" (SCOTT, 1995). Na primeira situação, trata-se de uma permanência da luta posseira, em que os papéis de gênero eram definidos em termos tradicionais (patriarcais), ainda que na prática as mulheres assumissem uma polivalência de atividades.

Ele disse [o líder do acampamento]: - Não, negócio aqui em acampamento é duro, quem tem que vir e ficar mesmo é os homens, as mulher não, ainda não. Quando chegar a vez da mulher vim as mulher vão vim, mas por enquanto tem que ficar são os homens (ALBUQUERQUE, 2013).

Neste espaço no qual o público e o privado deveriam estender suas fronteiras tênues para as relações de gênero, assimetrias continuam operando e ressignificando para além das relações primárias (essas recorrentemente naturalizadas), derivadas não somente da cultura camponesa, mas das políticas públicas: a conquista da terra está interditada às mulheres. Mais do que uma formalidade jurídica - a mulher não pode ser titular de uma terra da reforma agrária - trata-se da produção de uma inexistência jurídica, política e produtiva. Assim, a política pública exerce um poder formador na reprodução de uma cultura sexista machista e de negação de direitos de cidadania às mulheres que estão para além do direito à terra. Neste último, trata-se de respaldar "o não acesso a propriedade da terra por ser considerada incapaz de gerenciar a unidade produtiva" e "incapaz de assumir a posição de chefe da unidade familiar" ( BEZERRA, 2008, p. 22). Reproduz-se uma divisão sexuada do trabalho desdobrada nas esferas pública e privada.

A esfera pública é o lugar da visibilidade das pessoas, dos fenômenos, dos processos sociais e da construção das ideias e simbologias que fazem girar o mundo da vida. É o lugar da grande política como diz Habermas (1987). É aqui que o trabalho dos homens se realiza com toda a sua carga de simbologia, tido como racional e impregnado de valor social. Enquanto que a esfera privada, onde se realiza o trabalho da mulher, considerado imanente e improdutivo, é carregada de estereotipia e sem valor social (TORRES, 2012, p. 206).

De certa forma, a centralidade da atuação sociopolítica presente na narrativa de Zefa serve de indício de como essa mulher se vê (re)elaborando suas identificações, nomeando um lócus para seu agenciamento. Ela assume a decisão de lutar pela terra como um projeto para a reprodução da família: a cidade não era lugar adequado para criar os filhos. No Acampamento Santa Maria, ela insistiu em permanecer e assumir uma atividade. Quando conquistaram a terra, seis meses depois, ela já era uma referência no coletivo. Ela conta que 
foi convidada para participar do sindicato de Itupiranga e ressalta que pediu um tempo para pensar "porque eu não sabia, eu não entendia nada".

A narrativa de Zefa dá conta de uma trajetória como liderança local por vários anos dirigente da Associação dos Assentados, bem como membro da diretoria do STR de Itupiranga, sem deixar de enfrentar a questão do seu reconhecimento, enquanto mulhercamponesa. Foi como membro da diretoria da FETAGRI - Regional Sudeste que elegeu o foco das tensões e limites de sua atuação, mesmo nos movimentos de silenciamento estratégico, relacionando-os a questão de gênero.

Eu ficava calada no meu canto. Às vezes, o [fulano] puxava alguma prosa comigo. Zefa conversa, Zefa. - Eu vou conversar o quê, que vocês não deixa? Vocês tão aí conversando só coisa de vocês mesmo, eu vou me entrar na conversa? Aí eu não me sentia bem nesses momentos (ALBUQUERQUE, 2013).

Na FETAGRI, Zefa assumiu a Secretaria de Gênero, o que era o indício de que devia tratar-se de assunto das 'mulheres'. Nas diretorias dos sindicatos, como na FETAGRI, predominava a presença dos homens e a questão de gênero tinha uma entrada formal, por conta da necessidade de representação das mulheres (30\%), e uma entrada política advinda da organização das camponesas. Dados de 2014 mostram que as mulheres ocupam geralmente os cargos de secretaria e de gênero nos STTR's ligados a FETAGRI do Sudeste paraense ${ }^{14}$. Dos 27 sindicatos, 21 são dirigidos por homens e 6 por mulheres. Por outro lado, as 17 Secretarias de Mulher existentes estão ocupadas por mulheres. Os cargos que tratam de finanças, produção agrícola e política agrária são ocupados majoritariamente por homens e os cargos tratando de juventude, terceira idade e secretaria geral, são ocupados nalguns casos exclusivamente por mulheres. Sobre esse contexto, Zefa reflete:

[...] a mulher dentro do movimento tá ainda muito, é muito discriminada pelos homens. Se não tivesse cota, mulher nem falava, como tem essa cota de $30 \%$ a mulher ainda tem a voz lá dentro, ainda fala alguma coisa, ainda tem como ficar na diretoria e se não tivesse a mulher nem essa oportunidade não tinha ( ALBUQUERQUE, 2013).

Para a narradora, não se tratava apenas de ocupar espaços no movimento de luta pela terra, mas sim o desejo de empoderamento de sua fala ressignificada para uma outra Zefa: solta, falante, convicta de seus pensamentos: dispositivo-mulher ${ }^{15}$.

\footnotetext{
${ }^{14}$ Pesquisa documental (Atas das eleições e posse de STTRs) realizada na sede da FETAGRI Sudeste do Pará em junho de 2014 pela bolsista Kezia Vieira de Sousa.

${ }^{15}$ A metáfora foi pensada, a partir de Giorgio Agamben (2009), quando pensa o dispositivo como uma função estratégica e concreta se inscrevendo sempre em uma relação de poder.
} 


\begin{abstract}
Aí, então através desse tipo de coisa assim acho que foi onde eu fui, como é que fala? criando outra Zefa, me soltando mais porque eu era muito tímida, eu era boa pra dançar forró, mas pra mim tá conversando assim, me abrir assim pra conversar eu não gostava muito não, eu não me soltava. Aí depois que eu vim pro movimento é que eu tô me soltando assim aos pouquinho. Hoje, o menino lá da IMATEL, [...], diz assim: -Zefa, mas tu mudou demais, Zefa! Mudou. Ainda bem que tu mudou pra melhor! Que a Zefa de antigamente mal abria a boca. Mas era mesmo. Eu mal conversava, eu não gostava de conversar, as vezes eu passava o dia todim numa reunião e ninguém me via assim ou dizia assim a Zefa tá aqui. Eu não, eu dizia meu Deus o quê que eu vou falar, eu não sabia nem por onde começar, o quê que eu ia perguntar e eu morria de medo de falar alguma coisa e eu não tá falando no sentido que era aquele tema ( ALBUQUERQUE, 2013).
\end{abstract}

Essa voz reforça um olhar crítico sobre as relações de poder de gênero no interior do movimento: o poder de dizer a palavra, dependendo da posição e da relação em que estão inseridos os sujeitos. O sentido produzido pela narrativa de Zefa é de que os homens detinham (detém) o poder da palavra:

aqueles que possuem como direito próprio ou delegado, o poder de dizer a palavra que se apresenta como conhecimento legitimo e necessário e que, portanto, consagra uma ordem social que, por sua vez garante a "verdade" e o poder da palavra legitima (BRANDÃO, 2006, p. 13).

Para Zefa, essa é a síntese dos seus limites e de conquistas no movimento: a sua palavra teve que ser constituída e a sua pronúncia precisou ser audível, para ter um lugar conquistado. Nada lhe foi gratuitamente concedido: "aí eu não falava nada, ficava só ouvindo, aí nesse meu ouvindo eu fui aprendeno e aprendeno e aprendeno mais e mais, aprendi com o tempo mesmo dentro do movimento, foi que eu aprendi a me soltar" ( ALBUQUERQUE, 2013).

No ato narrativo, essa voz procurou alinhavar sentidos para sua trajetória no Movimento, sobrelevando seus aprendizados: "a minha intenção era só aprender as coisas né, porque eu não sabia mesmo de nada". Sua conquista principal, dizer a palavra: "agora eu aceito, agora já me sinto dentro do movimento, porque eu já tava mais ou menos sabendo por onde entrar e por onde sair né, porque eu não sabia de nada” (ALBUQUERQUE, 2013).

Ultimamente, Zefa está priorizando o trabalho no seu lote de terra, evidenciando o lugar fundamental que ela ocupa na reprodução da família, mas pretende voltar a estudar, reforçando o sentido atribuído a sua trajetória e para a conquistas de outros espaços territoriais-simbólicos para sua fala e para a reconstrução de seus agenciamentos.

Agora depois que eu me afastei mais do movimento que eu vim pensar isso que eu tenho que continuar meus estudos, eu vendo minhas fias tudo se formando, aí elas me cobrando também. -Mãe, a senhora não pode ficar parada a senhora tem que 
continuar, tem que estudar mãe. A senhora tem que ver que a senhora é a Zefa não pode parar não. E aí, por as minha filha, e o apoio que o meu esposo dá, ele diz: não, nega é pra estudar. E eu vou estudar, vou voltar ( ALBUQUERQUE, 2013).

\section{OS SENTIDOS DA ROÇA DESDOBRADOS EM RESISTÊNCIAS...}

...porque a palavra é um ato de poder, o que equivale afirmar que ela não é apenas um entre seus símbolos, mas o seu exercício

Carlos Rodrigues Brandão

Os imaginários sobre o campesinato, em sua grande maioria, professam um olhar caricatural, não sendo ainda a toa o número infindável de 'mitos' nostálgicos sobre o 'homem' do campo, geralmente 'Adâmico' normatizado e domesticado pela tríade (Deushomem-natureza). Corpo-voz-bíblico-missionário-mutilado. Trabalhador da terra, humilde, modesto e fadado à subordinação.

Repensemos essa questão, então, para a mulher. Tal como Eva, complementar a Adão e com 'desejos' condicionados ao dele. Identificações prêt-à-porter (ROGERS, 2006).

Nas micropolíticas ${ }^{16}$ do cotidiano, essas vozes do campesinato feminino, sendo escutadas e reinterpretadas, parecem falar contrariando o tom 'pessimista-problemático' dado a voz subalterna por Spivak (2010). Esses discursos, parecendo subterrâneos e inaudíveis, parecem desautorizar as forças majoritárias e redutoras desenhando o papel feminino na luta pela terra. Zefa e Dagmar dão adeus, em compasso com as experiências da luta, ao corpo-vozprisão, “Lócus do Dever e da Obrigação Moral” ( ROGERS, 2006, p. 199), reinscrevendo, sem abrir mão dos medos, das hesitações e dos silêncios estratégicos, o destino de um coletivo. Suas vozes vibram, brigam e gritam acompanhadas do corpo vibrante. Querem ser linhas de fuga dos silenciamentos e proibições de suas experiências micro ou macro sociais, assumindo protagonismos nas dinâmicas familiares e da luta pela terra.

Essas vozes ainda partem de um lugar de poder desigual, mas não mais inexistente no interior das versões hegemonizadas por homens. Não são, necessariamente, narrativas de oposição, mas que apresentam diferenças, e, por isso, alargam o campo da resistência camponesa na produção de sentidos, para suas lutas.

São narrativas de "gênero":

\footnotetext{
${ }^{16}$ As micropolíticas, compreendidas como: platôs, zonas de intensidade contínua, linhas ligadas a determinadas dimensões de multiplicidades, linhas de fuga, círculos de convergência. Agenciamentos maquínicos de desejo e coletivos de enunciação (DELEUZE \& GUATTARI, 1996, p. 27).
} 
palavra duvidosa ou esquiva por sua utilização para coisas diferentes - , neste caso a feminilidade, a condição de mulher de muitos rostos, que não apenas espera e tece (o tempo, a nostalgia e a fidelidade, etc), mas que atua sobre condicionamentos (restrições) e obstáculos (CURRIÓ, 2010, p. 13).

Não seriam vozes feministas em seus clichês mais ressonantes. Seriam apenas vozes:

se quisermos evitar que a guerra politicamente correta dos e pelos gêneros se transforme numa guerra politicamente nefasta para a vida, será preciso travar simultaneamente uma guerra contra a redução das subjetividades a gêneros, a favor da vida e suas misturas (ROLNIK, 1996, p. 121-122).

Enfim, encontramos mulheres icônicas exercendo o poder da palavra, numa perspectiva relacional e intersticial (desdobrando a cultura e a memória camponesa no sudeste do Pará) e agonística (agenciando um campo de luta no limiar da inexistência/existência). O 'sentido da roça' e o 'dizer a palavra' inserem Outras visões e percepções às experiências de resistência sociocultural camponesas.

\section{REFERÊNCIAS}

\section{LIVROS:}

AGAMBEN, Giorgio. O que é o Contemporâneo? Tradução de Vinícius Nicastro Honesko. Chapecó: Argos, 2009.

ALMEIDA, Alfredo W. Berno de. Antropologia dos archivos da Amazônia. Rio de Janeiro: Casa 8/ Fundação Universidade do Amazonas, 2008.

BHABHA, Homi K. O bazar global e o clube dos cavalheiros ingleses: textos seletos de Homi Bhabha. Organização de Eduardo F. Coutinho. Tradução de Teresa Dias Carneiro. Rio de Janeiro: Rocco, 2011.

BHABHA, Homi. O local da cultura. Tradução de M. Ávila, E. L. de Lima Reis e G. R. Gonçalves. 2a reimpressão. Belo Horizonte: Editora da UFMG, 2003.

BRANDÃO, Carlos Rodrigues. O que é educação popular. São Paulo, Brasiliense, 2006.

CARRIÓ, Raquel. "Prefácio". In: VARLEI, Júlia. Pedras d'água. Blocos de notas de uma atriz de Odin Teatret. Brasília: Teatro Caleidoscópio.

CASTRO, Edna. "Políticas de Estado e atores sociais na Amazônia contemporânea". In: BOLLI, Willi; CASTRO, Edna; VEJMELKA, Marcel (Orgs.). Amazônia: região universal e teatro do mundo. São Paulo: Globo, 2010, p. 105-122.

CERTEAU, Michel de. A invenção do cotidiano. 1. Artes de fazer. (Trad.) $6^{\mathrm{a}}$ edição. Petrópolis: Vozes, 1994. 
COLOMBO, Fausto. Os Arquivos Imperfeitos. Tradução de Beatriz Borges. São Paulo: Ed. Perspectiva, 1991.

DELEUZE, Gilles; GUATTARI, Félix. Mil Platôs. Capitalismo e Esquizofrenia. Vol. 3. Tradução de Aurélio Guerra Neto, Ana Lúcia de Oliveira, Lucia Claudia Leão e Suely Rolnik. São Paulo: Ed. 34, 1996.

FROTSCHER, Mónica. "Desigualdades e diferenças: história oral e movimentos sociais”. In: LAVERDI, Robson et al. (Orgs.). História Oral: desigualdades e diferenças. Recife: Ed. Universitária da UFPE; Florianópolis: Ed. da UFSC, 2012, p. 218-230.

GONSALVES, Elisa Pereira. "Pesquisar, participar: sensibilidades pós-modernas". In: BRANDÃO, Carlos Rodrigues e STRECK, Danilo R. (Orgs.). Pesquisa participante: a partilha do saber. Aparecida, SP: Idéias \& Letras, 2006, p. 245-258.

LIMA, Nei Clara de. Narrativas orais: uma poética da vida social. Brasília: EdUnB, 2003.

PIRES FERREIRA, Jerusa. Armadilhas da Memória. São Paulo: Ateliê Editorial, 2004.

PROUST, Marcel. No Caminho de Swann. Tradução de Mário Quintana, 6a. ed. São Paulo: Editora Globo, 1981.

ROLNIK, Suely. "Guerra dos gêneros e guerra aos gêneros". Estudos Feministas, v. 4, n. 1, p. 118-123. $1^{\circ}$. semestre, 1996.

ROLNIK, Suely. Cartografia sentimental: transformações contemporâneas do desejo. Porto Alegre: Sulina/Editora da UFRGS, 2014.

SANTOS, Boaventura de Sousa. "Para além do pensamento abissal: das linhas globais a uma ecologia de saberes". In: SANTOS, Boaventura de Sousa; MENESES, Maria Paula (Orgs.). Epistemologias do Sul. São Paulo: Cortez, 2010, p. 31-67.

SCOTT, Joan W. "Experiência”. In: SILVA, Alcione L. da, LAGO, Mara Coelho de S. e RAMOS, Tânia Regina O. (Orgs.). Falas de gênero. Santa Catarina: Editora Mulheres, 1999. p. 21-55.

SCOTT, Joan. "História das mulheres". In: BURKE, Peter (Org.). A escrita da história: novas perspectivas. Tradução de Magda Lopes. São Paulo: Editora UNESP, 1992, p. 63-95.

SOUZA, Lynn T. M. de. "Hibridismo e tradução cultural em Bhabha". In: ABDALA JUNIOR, Benjamin (Org.). Margens da cultura: mestiçagem, hibridismos \& outras misturas. São Paulo: Boitempo, 2004, p. 113-133.

SPIVAK, Gayatri Chakravorty. Pode o subalterno falar? Tradução de Sandra Regina Goulart Almeida; Marcos Pereira Feitosa; André Pereira. Belo Horizonte: Editora da UFMG, 2010.

THOMPSON, Eduard Palmer. "O termo ausente: experiência". In: . A miséria da teoria ou um planetário de erros: uma crítica ao pensamento de Althusser. (trad.). Rio de Janeiro: Zahar, 1981, p. 180-199.

TORRES, Iraildes Caldas. "Reflexões sobre trabalho leve e pesado das mulheres na Amazônia". In: 2012, p. 197-209.

VELHO, Gilberto. Projetos e Metamorfoses: Antropologia das sociedades complexas. Rio de Janeiro: Zahar, 1994.

ZIZEK, Slavo. Seis reflexões laterais. Tradução de Miguel Serras Pereira. São Paulo:

Boitempo, 2014. 
ZOURABICHVILI, François. O Vocabulário de Deleuze. Tradução de André Telles. Rio de Janeiro: CIENTI/UNICAMP, 2004.

ZUMTHOR, Paul. Performance, recepção e leitura. Trad. Jerusa Pires Ferreira e Suely Fenerich. São Paulo: Hucitec/Educ, 2000.

\section{ENTREVISTAS:}

ALBUQUERQUE, Josefa Sousa e Silva. Entrevista Oral [gravada] realizada pelo autor (a) e a bolsista Kezia Vieira de Sousa. PA Grande Vitória, Marabá, 27 nov. 2013. 1h53min.

SOUSA, Maria Dagmar Ferreira de. Entrevista Oral [gravada] realizada pelo autor (a) e pela bolsista Maria Marlete Ferreira Gomes. Marabá, 30 nov. 2013. 01h50min.

\section{MONOGRAFIAS, TESES E DISSERTAÇÕES:}

BEZERRA, Rosemayre Lima. Mulheres posseiras: uma história de luta silenciada. 2008. (Monografia) Graduação em Ciências Sociais - Campus Universitário de Marabá, Universidade Federal do Pará, Marabá.

PEREIRA, Airton dos Reis. A luta pela terra no sul e sudeste do Pará: migrações, conflitos e violência no campo. 2013. Tese (Doutorado em História) - Programa de Pós-Graduação em História, Universidade Federal de Pernambuco, Recife.

ROGERS, Paulo. Os Afectos malditos. O indizível nas sexualidades camponesas. 2006. Tese (Doutorado em Antropologia) - Programa de Pós-Graduação em Antropologia Social, Universidade de Brasília, Brasília.

\section{REVISTAS ACADÊMICAS:}

GUIMARÃES NETO, Regina Beatriz. "História, politica e testemunho: violência e trabalho na Amazônia brasileira. A narrativa oral da presidenta do Sindicato dos Trabalhadores Rurais de Confresa (MT), Aparecida Barbosa da Silva”. História Oral, v. 13, n. 1, p. 53-86, jan.-jun. 2010.

PORTELLI, Eduardo. "Forma e significado na história oral. A pesquisa como um experimento de igualdade”. Tradução de Maria Therezinha Janine Ribeiro. Projeto História, n. 14, p. 7-24, fev. 1997.

SALVATICI, Silvia. "Memórias de gênero: reflexões sobre a história oral de mulheres". Tradução de Luiz Antonio R. R. Campos. História Oral, v. 8, n. 1, p.29-42, jan-jun. 2005.

SCOTT, Joan Wallach. “Gênero: uma categoria útil de análise histórica”. Educação \& Realidade, v. 20, n. 2, p. 71-99, jul./dez. 1995.

THOMSON, Alistair. "Recompondo a memória: questões sobre a relação entre a História Oral e as memórias”. Projeto História, São Paulo, n. 15, p. 51-84, abr. 1997. 